\title{
Analysis on Characteristics of Network Literature Reading by Teenager
}

\author{
Changmin Wang \\ Feixian County Branch School \\ Linyi University \\ Linyi, China
}

\begin{abstract}
In the 21st century, the network literature reading has become the main reading way of Chinese teenagers. But network literature has extensive contents and rich resources, which will bring mental pollution to teenagers while satisfying their interest and spiritual demand. As a result, the network literature reading education is extremely urgent.
\end{abstract}

Keywords—network reading; network; teenagers

\section{INTRODUCTION}

Traditional reading refers to the process of acquiring information from paper text, such as newspapers, books and periodicals, the reading objects are mainly words, including symbol, formu la and chart, etc. Entering the 21 st century, with the development of the times as well as science and technology, the Internet network with computers, cell phones and other electronic products as carriers has a growing impact on the world, penetrating into every corner of the people's daily life, becoming the important tool of communication and reading at present. "Along with the rapid development of Internet, the network reading is increasingly becoming the most promising way of reading" [1], and it has an overwhelming developing trend. In the face of this situation, the teenagers who are full of curiosity and exploration to new things have rapidly grown to be the major network reading group. Network reading refers to the reading activity obtaining information from the network culture, it is "a process of completing meaning construction at information receiving end of reader, obtaining network text (including text, pictures, audio, video and other multimedia information) by virtue of related hardware facilities such as computer and the Internet, and displaying or playing through computer screen and e-book reading terminal window" [2]. The information carried by network reading is emotional, intuitive and comprehensive, convenient, novel and abundant, integrating preview, listening and reading in terms of form, which has meet the teenagers' increasing psychological and spiritual needs, made their reading vision broader and reading taste stronger, and has attracted and affected the teenagers, and has become a main way for teenagers' information acquisition, interactive learning, living and entertainment gradually. This generation of teenagers grows up with the network in the same period; therefore they are called by the researchers as "Google Father, IM (InstantMessage) Mother", namely "Net generation" [3].
Network literature reading is one form of the network reading, it is a reading process of the original literary works, literary texts and the network art works containing some literature elements that take network as the carrier, take the Internet as display platform and communication media, and that expressed through hypertext links and multimedia deduction. It can be divided into online and offline reading, which is the same as network reading. Network literature reading is accounting for an increasing proportion in teenagers' reading behavior, and it has become an important way for teenagers' lifelong learning ability, which can effectively promote teenagers to gradually improve their knowledge structure and enhance humanistic accomplishments. But there are some problems in the network literature reading, for example, the complex and varied content, the uneven quality, explosive expanded amount of information and imperfect health supervision system, etc. Teenagers' resolution and self-control ability is poor due to the limitations of age and experience, so they are easy to go astray. It is necessary for social regulatory authority to survey and research teenagers' network literary reading, and to effectively guide and improve their reading literacy.

\section{CURRENT SitUATION OF TEENAGERS' NETWORK LITERATURE READING}

Some network writers cater to the fond of teenagers for profits, and they pay attention to the novel content and fashionable expression form, but ignore the health content, revealing many deficiencies in the outlook on life, values and standardization of Chinese characters carried by network literature. The Investigation result analysis on colleges made by the author shows that college students' Internet penetration rate reaches $100 \%$, the distribution rate of students who surf the Internet more than an hour per day is up to $85 \%, 65 \%$ of the students often surf the Internet through mobile terminal; $92 \%$ of the students think network reading is the main channel to obtain information, which has far exceeded traditional reading; $87 \%$ of college students conduct online leisure activities such as chatting to make friends, watching movies, reading network literature, listening to music and playing games through online communication tools and web; $60 \%$ of college students browse news and current affairs through the network; $52 \%$ of college students often use network resources to query data for professional and other kinds of learning. The number of college students who often read network literature 
has far exceeded that of middle school students, reaching $65 \%$. The college students' network literary reading level is broader than that of middle school students, involving not only the fantasy and romance literatures with multiple reader levels, but also including the aspects of history, officialdom, work place, and humanities, etc. Surveys show that, with relatively mature psychology and the broad knowledge structure, college students can take initiative to read the network literatures that are beneficial to physical and psychological health more effectively than middle school students. And the study also shows the middle school students need education and proper guidance from teachers, parents and society in terms of network literature reading.

\section{CHARACTERISTICS OF TEENAGERS' NETWORK LITERATURE READING}

\section{A. Diversified and Portable Reading Tool}

With the increasing development of science and technology, network literature reading tools are more and more advanced, which can use a variety of electronic devices to download online or offline, such as desktop computers, laptops, tablet PCs, e-book reader, CD and MP3 reader, mobile phone and so on. The fast update of mobile technology has made network literature reading at anytime and anywhere a reality. Compared with the traditional text reading, network literature reading has more convenient and quicker searching functions, with a larger amount of information, cheaper price and it is more convenient to carry about. The use of new technology make readers do not limited to the reading from desktop computer, but they can read at anytime and anywhere using a variety of postures, regulating people to a certain degree, and bringing about mental relaxation. For teenagers who love freedom, this way of reading fit them more than that of traditional text reading, but it is not conducive to body healthy and is unfavorable to the improvement of reading literacy.

\section{B. Open Reading Environment and Rich Resources}

The openness of network literature reading environment not only lies in its portable reading tools, the open reading unlimited by time and place, but also lies in that the network can be opened and shared beyond regional and national border, enabling the users from different countries and regions to exchange information beyond time and space limit. The network's unique hypertext links and powerful search function also make the network a great information resource database, with amount of information growing by leaps, presenting the open vast amounts of information to the readers. But the openness has also brought about pollution to online literature reading environment, and large amount of repeated, false, vulgar and superficial information make the network reading environment not that pure enough, which is very easy to mislead the teenagers.

The source of network literature reading resources is abundant, including not only the Qidian.com, Zhulang.com, Jinjiang Literature City (Jinjiang Original Net), Xiaoxiang Academy, Hongxiu.com, Rongshuxia, and other large original article and novel reading bases, but also the comprehensive base of literature reading of reading channel in the large websites such as Sina.com, Netease, Tencent, and Dangdang, and even the national famous BBS such as Tianya, MOP, Xici.net and Shui $\mathrm{Mu}$ Tsinghua as well as the original literature bases of local famous BBS such as The 19th Floor, Dachu and HuaiYin. And there are countless all kinds of literature websites, blogs and space. As for young readers who love network reading, they have many choices, but the possibility of misleading by harmful website is greatly increased.

\section{Extensive Reading Content and Popular Subject}

Network literature involves extremely broad contents. Through the comprehensive literature works of Sina and Tianya, there are numerous contents about official circles, medicine, agriculture, shopping malls, intelligence, and citizen reality, and even health maintenance, essays, education experience and biographies, which are extremely broad. The focus of young readers' network literature reading content is narrow, taking Qidian.com with the most readers and the highest click rate as an example, its classification column in the homepage includes 16 categories such as fantasy, martial arts, history, military, urban, literature, and schoolgirl. Teenagers pay more attention to fantasy, martial arts, myth and romance, the reading level is narrow and single, which is not conducive to improvement of reading literacy. The writers of network literature are mostly the common people. In order to attract readers' long-term tracking reading, writers will deliberately cater to readers' preferences, such as the creation of martial arts, grave robbery and history, and even the direct interaction with readers and joint creation, resulting in strong popularity of the works' theme. But overall, with are filled in the popular network literature that the teenagers like to read are not the traditional literature and useful literary, but the black violence literature represented by online fantasy, gray literature represented by tomb robbery, pink literature represented by romance and youth, yellow literature represented by eroticism lust, which is easy to cause bad influence on teenagers who are lack of resolution and selfcontrol ability, leading to the deviation of their life's trend.

\section{Special Reading Subject and Interactive Process}

The extensive and abundant reading content of network literature has strong attraction for teenagers, making them to choose corresponding network literature according to their personal interests, hobbies and viewpoint, and become the main body of reading. And this part of reading group is young with low academic degree and strong active reading. They are happy to follow up the works that they are interest in for a long term, which also shows that as reading subject, teenagers are deeply influenced by network literature, highlighting the particularity of reading subject. But teenagers are in the special period of mental growth yet haven't matured. Because of the characteristics of their knowledge structure defects, strong curiosity, weak self-control power to resist temptation, etc., the negative impact of network literature on youth is multiplied.

Compared with other reading main body of network literature, young readers prefer instant communication with writers while reading, and give suggestions to the works' characters, structure and plot development. In such interaction, 
the boundary between writers and readers dis appeared, and the language of works has distinct personality, vivid and approachable. The works become the creation made jointly by writers and readers, and the creation process becomes a literature feast. In addition, the youth of network literature reading are happy to make a sequence for the original novel with strong resonance and conduct the creation with same theme but different leading role, make the network literature creation the large scale art activity with collective participation. And the focus is transformed from "author center", "text center" down to the "reader center", with the will and interests of all participants being displayed. But teenagers are in the rise and busy period of learning, and quite a number of teenagers admit that they have burned the midnight oil, to finish a favorite network literature work. But on the class, they feel sleepy or are still addicted to the ridiculous thoughts in the book, and cannot listen carefully. So me other fall in love after they read the network romance novels, pursuing the imple mentation of virtual romance in reality or on the network. Part of the network literature works have depressive style and negative theme, having impact on the main body of reading, making them lack of the vitality, energy and entrepreneurial spirit that teenagers should have. The excessive free way of network literature writing influences the young readers, making their writing language vulgar.

\section{E. Strong Timeliness of Reading and Uneven Quality}

Network literature reading pays attention to entertainment. As the main body of reading, teenagers tend to linger in the plot due to the influences of personal qualities, age characteristics, schoolwork burden and the limitation of their spare time. And there is great randomness and uncertainty while choosing the reading content, with strong timeliness of reading object. In addition, the contents written by the author will change as reading subject's focus often changes, resulting in strong timeliness of reading object, and large amount of works with same theme and within the same period, are similar, of which the contents are simple, scattered and optional. Network literature website has rigid regulations for the length of works and the number of works to be updated. In order to meet these requirements, the authors update their content every day. Timeliness is guaranteed, but their though is not smooth. So they deliberately write more about the landscapes and dialogues to reach the number of words. Thus the article is lengthened, but the plot is dilatory with verbiage. The rapid development of electronic technology enables network literature reading to make headnote, sidenote and experience which is the same as traditional text reading. The timeliness of the technology is increased, but also leads to network literature reading lack deep reflection and deep mining. Network literature reading has strong entertainment with uneven quality, and is called by some researchers as shallow reading and fragment reading, belonging to the fast-food culture. Compared with the traditional text reading, network literature reading has superficial thinking, weak systematicness and insufficient literariness. Many works are isolated from the reality, gaining the victory through fantastic imagination and tense plot. Some writers even declare that they are not "writers", as they only write entertainment and relaxed small text. The works with black violent theme such as fantasy online games and the works of eroticism lust are favored by the young readers, for example, the Desecration in early stage, Animal Blood Boiling in the middle stage, and Qinglian Record. In recent years, network technology and application conditions continue to improve, and network literature has a steady development, having given birth to a group of higher level network professional writers, among them the more famous ones include Nanpai Sanshu, Feiwo Sicun, Bobo, Guman, Tianxia Bachang and Miaojuan, etc. Their novel language has unique characteristics with novel content, a huge number of online readers and relative stable readers. But at present, among the countless network literature works, those with high quality only account for a small proportion. We shall lead the leaders of well-known network literature websites to pay attention to long-term contract with and continuous cultivation of high level writers, as well as continuous development of high quality works, to improve the quality of network literature itself.

\section{CONCLUSION}

The development of the society, the advent of information age and the network popularization make the traditional text reading transform to network literature reading, which is the inevitable trend of era development. Although the influence of network literature writers and the quality of their works cannot compare with the traditional classical text reading, the irreversible trend of network literature reading development has a huge impact on the teenagers. The teenagers' reading ability directly affects their growth direction, professional ability and their role in society; the reading rate and reading ability are directly related to the national soft power and the comprehensive national strength, affecting the overall social civilization degree, determining the nation's basic qualities, creativity and development potential. The teenagers' reading level also marks the civilization of a country and the society. The particularity of teenagers as the main body of network literature reading, requires the education workers and the society to pay attention to the transformation from traditional reading to network reading of the information age, in the way of thinking of keeping pace with the times, and based on the characteristics of network literature reading, thus to offer effective reading education and guidance to teenagers. Teenagers have become the main body of network literature reading, so it is urgent to imp lement network literature reading guidance to them. The society will also be liable to lead the creation groups of network literature with the main theme and elegant taste, to improve the overall quality of network writers, so as to promote the true healthy and vigorous development of network literature; school education shall provide strong and positive guidance for teenagers' network literary reading in class in a timely manner; parents give teenagers the correct guidance and supervision by their words and deeds in daily life.

\section{REFERENCES}

[1] Liu Muyu. Report on Creative Industry Research on Beijing Culture [M] . Beijing: Capital Normal University Press, 2008

[2] Liu Yuanrong, Wang Fengying. Research on Network Literature Reading [M]. Changchun: Jilin University Press, 2010: 31 
[3] Written by Don Tapscott (US), Translated by Chen Xiaokai, Yuan Shipei. Growing up digital: The Rise of the Net Generation [M] Dalian: Dongbei University of Finance \& Economics Press, 1999: 2 